\title{
QUALITY CONTROL OF SPUTUM FOR AFB EXAMINATION IN BIG HOSPITALS AND PRIVATE LABORATORIES
}

The $22^{\text {nd }}$ IUATLD Eastern Region Conference is going to be held in Kathmandu from $22^{\text {nd }}-25^{\text {th }}$ September, 2003. In this conference, tuberculosis would be the major issue. Tuberculosis is one of the foremost public health problems in Nepal, causing an enormous burden of suffering and death. ${ }^{1}$ Recent estimates suggest that about $60 \%$ of the adult population is infected with the tubercle bacillus and each year about 50,000 people develop tuberculosis, over 20,000 of whom have infectious sputum smear positive disease. ${ }^{2}$ It is estimated that about 15,000 people die from tuberculosis each year. ${ }^{3}$ Among the diseases requiring admission in medical units in Bir Hospital, the central hospital of Nepal, tuberculosis was found to be the third and fourth commonest cause in the years 2053 and 2055 respectively. ${ }^{4,5}$

Nepal has come a long way in reaching the Global Targets for Tuberculosis Control. The data from National Tuberculosis Center show that from a situation in 1995 when the National Tuberculosis Program piloted DOTS in four districts with total population coverage of $1.7 \%$ it now has 315 DOTS centers and 1050 Treatment Sub-Centers in every one of the 75 districts in Nepal with $91 \%$ total population coverage. National Tuberculosis Center really deserves a compliment for its tremendous efforts. But it should not lead to complacency. This is particularly so in urban areas where the need of Private Public Partnership is increasingly felt in the field of tuberculosis control. The rapid increase of HIV/AIDS in the country and cross border tuberculosis spread and management are other difficult areas.

There is high concentration of population, including tuberculosis patients, in urban areas. Sputum for AFB examination is the most important tool for the early diagnosis and proper management of tuberculosis patients, especially from the point of view of tuberculosis control. Quality control of sputum AFB examination, where all the positive and $10 \%$ of negative slides in each laboratory are reexamined, is vital not only for clinical management but also for control of tuberculosis. Under the National Tuberculosis Control Program, there are 299 peripheral laboratories in the 5 regions carrying out sputum AFB examination, with 5 reference laboratories carrying out the Quality Assurance. It is satisfying to know the NTC report of $98 \%$ overall agreement of the sputum AFB examination in the year 2002. Quality control of sputum AFB examination is similarly required in big hospitals and private laboratories in urban areas. Currently it is not surprising that sputum AFB examination done freely in a health post may be more reliable than expensive sputum examination done in private laboratories or big hospitals in urban areas!

Pulmonary tuberculosis in adults, i.e. the post-primary TB, classically originates in the apices of the lung. Atypical presentation of tuberculsos is quite well known with patients with diabetes or HIV and the elderly. ${ }^{6,7}$ In immunocompromised patients, there may also be less inflammation and cavitation; even cough and hemoptysis may become less common. ${ }^{7}$ Patients with diabetes or HIV and the elderly may exhibit atypical clinical or radiological findings. Lower lobe infiltrates were reported to occur in $20 \%$ of diabetic patients with reactivation $\mathrm{TB} .{ }^{8}$ In the elderly, pure apical lesions were seen in only $7 \%$ while $48 \%$ had middle field or basal lesions and $46 \%$ had a mixed pattern. ${ }^{8}$ But atypical radiographic presentations are not necessarily encountered only in the elderly and have been found equally in the elderly and younger adults. ${ }^{8}$ With increasing diabetes, longevity and HIV/AIDS in the population, any opacity, not only the classical ones, can be tuberculosis until proved otherwise. The role of sputum AFB examination has increased much now. Delay in the diagnosis of tuberculosis due to the improper sputum AFB examinations done in places, where quality control is not done, could allow transmission of the disease to others, including the clinicians. Thus, National Tuberculosis Center and other tuberculosis control organizations should give due priority to the quality control of sputum AFB examination not only in the peripheral health posts but also in big hospitals and private laboratories in urban areas. Management of hospitals and private laboratories should also give full attention to the quality control of sputum AFB examination. 


\section{REFERENCES \\ 1. Bam DS, Smith I. Principles of effective tuberculosis control in Nepal. J Nep Med Assoc 1996; 34: 3-7. \\ 2. HMG/WHO. National Tuberculosis Programme Review. Kathmandu, Ministry of Health 1994. \\ 3. National Tuberculosis Centre. National Tuberculosis Programme: A Clinical Manual for Nepal. Thimi: NTC 1998. \\ 4. Singh DL, Manadhar KM, Bhattarai MD, et al. Review of causes of morbidity and mortality of the admitted patients in the medical wards of Bir Hospital in one year. Souvenir : III National Conference Society of Internal Medicine of Nepal 1997 :55}

5. Joshi NG, Shrestha S, Paudyal LB, Bhattarai MD. Activities of the General Medicine Unit: analysis of the admitted patients. Souvenir : Bir Hospital 110 ${ }^{\text {th }}$ Anniversary 1999: 8-13.

6. Satya Sri. Lower lung field tuberculosis. In: Satya Sri, ed. Textbook of Pulmonary and Extrapulmonary Tuberculosis. New Delhi: New Delhi: INTERPRINT 1993: 109.

7. Maher D, Chaulet P, Spinaci S, Harries A. Treatment of Tuberculosis: Guidelines for National Programmes. Geneva: WHO 1997: 21-2.

8. Abter EIM, Schaening O, Barbour RL, Lutwick LI. Tuberculosis in the adult. In: Lutwick LI, ed. Tuberculosis : A Clinical Handbook. London: Chapman \& Hall Medical 1995: 54 - 101.

\title{
4th National Conference
o n
Science and Technology
Science and Technology for 21st Century
}

\section{Retrospect and Prospects in Nepal}

\author{
March 23 - 26, 2004 (Chaitra 10-13, 2060) \\ Kathmandu, Nepal \\ Corresponding Address \\ Member Secretary \\ Organizing Committee \\ Fourth National Conference on Science and Technology \\ RONAST, Khumaltar, Lalitpur, Nepal \\ P.O. Box: 3323, Kathmandu, Nepal \\ Tel: 5547720, 5547717, 5547715 \\ Fax: 977-1-5547713 \\ Email: info@fncst.org, fncst@mos.com.np \\ Website: www.fncst.org
}

